\title{
Frontières
}

\section{Volant, Éric, Culture et mort volontaire. Le suicide à travers les pays et les âges, Montréal, Lilber, 2006, 414 p.}

\section{Julie Bolduc}

Volume 19, numéro 1, automne 2006

Enjeux politiques et mort

URI : https://id.erudit.org/iderudit/016649ar

DOI : https://doi.org/10.7202/016649ar

Aller au sommaire du numéro

\section{Éditeur(s)}

Université du Québec à Montréal

ISSN

1180-3479 (imprimé)

1916-0976 (numérique)

Découvrir la revue

Citer ce compte rendu

Bolduc, J. (2006). Compte rendu de [Volant, Éric, Culture et mort volontaire. Le suicide à travers les pays et les âges, Montréal, Liber, 2006, 414 p.] Frontières, 19(1), 111-111. https://doi.org/10.7202/016649ar

Ce document est protégé par la loi sur le droit d'auteur. L'utilisation des services d'Érudit (y compris la reproduction) est assujettie à sa politique d'utilisation que vous pouvez consulter en ligne.

https://apropos.erudit.org/fr/usagers/politique-dutilisation/
Cet article est diffusé et préservé par Érudit.

Érudit est un consortium interuniversitaire sans but lucratif composé de l’Université de Montréal, l'Université Laval et l'Université du Québec à Montréal. Il a pour mission la promotion et la valorisation de la recherche. https://www.erudit.org/fr/ 
de la philosophie politique. Dans une démocratie, l'éthicien est celui qui porte un éclairage sur les problèmes éthiques pour que le débat citoyen puisse s'effectuer sur une base qui cerne le ou les véritables problèmes.

Se référant souvent à sa carrière et à sa démarche personnelle, Daniel Weinstock explique comment I'éthique appliquée était considérée comme de la philosophie légère face à la métaéthique ou à la philosophie analytique pour lesquelles I'analyse conceptuelle constitue le vrai travail du philosophe. Pour lui, le champ de l'éthique est «celui des principes qui devraient régir nos interactions avec autrui » (p. 17) et le travail de l'éthicien philosophe, fondé sur sa recherche universitaire, consiste "à repérer les principes régissant le vivreensemble» (p. 15). Une telle conception de l'éthique exclut une réflexion sur les finalités de la vie humaine, les buts de l'existence, les comportements acceptables au regard de ces buts, car une telle conception unitaire de l'éthique est inconciliable avec le pluralisme des valeurs contemporain. Sont exclues aussi du champ de l'éthique les obligations envers soi-même pour se centrer sur les interactions avec autrui et les principes qui les régissent.

Considérant que les deux grandes familles qui occupent le champ des théories éthiques sont l'utilitarisme et le déontologisme, rejoignant en cela les premières éditions du livre Principles of Biomedical Ethics des auteurs Beauchamp et Childress (1979, 1983), Daniel Weinstock présente la tâche la plus urgente de l'éthique comme étant celle de «travailler à définir l'équilibre le plus défendable qui soit entre la protection de la sphère d'autonomie des individus protégée par les droits individuels et la protection du plus grand bien » (p. 19) pour le plus grand nombre. L'individu demeure toujours maître de sa décision; l'éthicien a la tâche de repérer les particularités moralement pertinentes de son domaine d'intervention, alors que des théories et concepts éthiques «illuminent certains des points les plus saillants de la moralité » (p. 19). Selon lui, la réflexion morale ne doit pas porter sur des cas simplifiés, mais plutôt sur des réalités complexes dans lesquelles des facteurs institutionnels jouent un rôle important. Éloquemment, il montre que même les choix familiaux comportent des incidences institutionnelles qu'il est nécessaire d'éclairer. En éthique, l'accent doit être mis non pas tant sur la responsabilité individuelle que sur l'influence des facteurs institutionnels qui modè- lent le comportement humain. Or la gestion d'une pratique comme I'utilisation thérapeutique de cellules souches provenant d'embryons humains ne requiert pas tant un débat sur la nature de l'embryon où plusieurs théories s'affrontent qu'une élaboration de " procédures de délibération et de décision » qui permettront de vivre avec les différends dans le respect d'autrui (p. 31). Au lieu de se centrer sur la responsabilité au regard du comportement individuel, la réflexion éthique doit plutôt faire porter son analyse sur les normes, sanctions et incitatifs institutionnels qui modèlent les comportements individuels.

L'éthicien doit donc posséder de nombreuses compétences. II doit être au fait des développements philosophiques mais aussi comprendre le contexte institutionnel où se posent les problèmes et enjeux éthiques et où interfèrent des règles et normes institutionnelles, tant formelles qu'informelles. À l'inverse de la révolution cartésienne, il s'agit de partir de l'institution pour aller vers I'individu. C'est donc après avoir défini des conditions de délibération et des procédures que seront définies les qualités de l'individu et surtout les traits de caractère et les comportements qui seront nécessaires au bon fonctionnement des institutions.

Le rôle de l'éthicien dans la Cité est donc de définir le plus clairement possible les enjeux éthiques dans une situation problématique, de préciser les valeurs conflictuelles de manière à ce que les débats d'éthique sociale s'effectuent sur des bases solides (p. 43). À ce titre, il peut devenir un conseiller auprès de différentes instances. La qualité de ses interventions reposera sur les liens qu'il établira entre sa recherche de nature philosophique et universitaire, d'une part, et les situations comportant des enjeux éthiques, d'autre part. Dans cette perspective, il est clair que tous les champs d'activité "sont traversés dès le départ par des considérations éthiques » (p. 47). Et l'éthicien pourra intervenir à titre d'accompagnateur auprès des groupes, des institutions, des gouvernements, sur des questions qui relèvent de son expertise universitaire.

Dans le domaine de l'éthique professionnelle, l'éthicien apparaît trop souvent comme un empêcheur. La tendance malheureuse à consigner les comportements permis ou défendus dans des codes de déontologie risque d'inhiber la réflexion éthique qui devrait accompagner les pratiques. Dans ce domaine, comme dans les autres, l'éthicien mettra en place une relation d'accompagnement. "Il doit éviter de porter des jugement définitifs sur des questions, il doit éclairer le débat, plutôt que s'y substituer» (p. 53).

Après des écrits très critiques sur l'éthique appliquée, notamment par Lajeunesse et Sosoe dans Bioéthique et culture démocratique (1996), il est bienvenu qu'un philosophe présente un visage positif de celui qui œuvre dans ce champ. Suivant l'argumentaire développé dans ce livre, des modifications s'imposeraient dans la manière $d$ 'institutionnaliser l'éthique au Québec et au Canada. En effet, les comités d'éthique de la recherche qui deviennent de plus en plus normatifs, appliquant les règles à la lettre, et les comités d'éthique clinique qui sont consultés à titre d'experts y gagneraient à accompagner le chercheur et le praticien dans leur démarche respective, plutôt que de poser, voire d'imposer leur veto.

Jocelyne Saint-Arnaud

\section{VOLANT, Éric \\ Culture et mort volontaire}

\section{Le suicide à travers \\ les pays et les âges \\ Montréal, Liber, 2006, 414 p.}

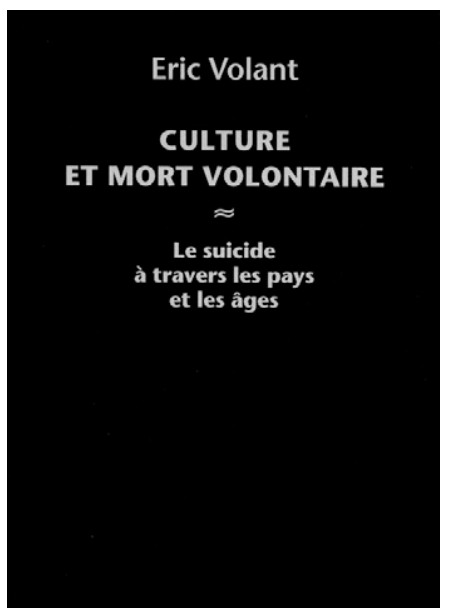

Culture et mort volontaire est un amalgame fascinant de faits, de statistiques, de littérature et de théories se rapportant à la mort volontaire. Éric Volant nous offre, avec ce livre qui vient remplacer son Dictionnaire des suicides publié en 2001, une véritable encyclopédie sur le suicide. II réunit dans cet ouvrage une quantité remarquable d'informations concernant la mort volontaire. Le livre, présentés sous forme de dictionnaire comprend un peu plus de trois cents articles. La psychologie, la philosophie, la sociologie, l'anthropologie, l'ethnologie, l'histoire et la psychanalyse côtoient les références aux différentes cultures et religions. $\mathrm{Ce}$ livre met en relief les diverses hypothèses et méthodes d'intervention développées face au suicide.

Culture et mort volontaire présente la position de plusieurs penseurs au sujet de la mort volontaire: Pythagore avec ses arguments arithmétiques et religieux, Kant et l'application de l'impératif catégorique, Durkeim établissant des rapports entre le suicide et le groupe social, Douglas et la formulation des six composantes du suicide ainsi que Landsberg, qui met en perspective les enjeux éthiques et religieux de la mort volontaire. On y retrouve également des statistiques sur le suicide concernant divers pays et continents.

Des éléments liés à la naissance du désir suicidaire sont présentés; on retrouve, entre autres: la grève de la faim, les problèmes de jeux, la pédophilie, l'économie, le chômage, l'échec, la maladie mentale. La prévention du suicide est aussi abordée avec le parasuicide, les lignes d'écoute, l'intervention et le travail du Centre de recherche CRISE à l'Université du Québec à Montréal. D'autres thèmes tels que: les lettres d'adieu, les martyres, les kamikazes, la honte, les funérailles sont introduits dans Culture et mort volontaire, de sorte que le livre couvre un vaste éventail de sujets en relation directe avec le suicide.

Éric Volant fait une place aux artistes ayant traité du thème du suicide au cours de leur carrière, par exemple Virginia Woolf, Marguerite Yourcenar, Albert Cohen et Antonin Artaud. Le livre dresse un bref portrait de leur œuvre en mettant l'accent sur la question du suicide ainsi que sur la manière dont les artistes l'ont traitée. Bon nombre d'entre eux ainsi que des politiciens, des personnalités publiques et des personnages de l'Antiquité ont choisi de mettre fin à leurs jours. C'est ainsi que l'on retrouve Adolf Hitler, Dalida, Marc Lépine, Claude Jutra et Vincent Van Gogh aux côtés de Judas Iscariote, Cléopâtre, Iphigénie, Jocaste, Héro et Léandre.

Culture et mort volontaire est un livre de référence qui viendra éclairer bien des débats, entre autres ceux autour de l'euthanasie ou du suicide assisté. II s'adresse autant aux néophytes qu'aux experts en matière de deuil, de mort et de suicide. Cet ouvrage donne une vue d'ensemble du phénomène suicidaire tout en soignant la qualité des informations fournies.

Julie Bolduc 